\title{
Presencia en el peridomicilio de vectores infectados con Leishmania (Viannia) panamensis en dos focos endémicos en el occidente de Boyacá, piedemonte del valle del Magdalena medio, Colombia
}

\author{
Erika Santamaría ${ }^{1}$, Nubia Ponce ${ }^{1}$, Yaneth Zipa ${ }^{2}$, Cristina Ferro ${ }^{1}$ \\ ${ }^{1}$ Laboratorio de Entomología, Instituto Nacional de Salud, Bogotá, D.C., Colombia. \\ ${ }^{2}$ Secretaría de Salud de Boyacá, Tunja, Colombia. \\ Introducción. En el departamento de Boyacá, los casos de leishmaniasis registrados de 1997 \\ a 2003 muestran un aumento en la incidencia a partir del año 2000 que puede corresponder \\ a una epidemia en el occidente del departamento. Además, la distribución de casos por sexo \\ y edad sugiere transmisión domiciliar. \\ Objetivo. Definir los vectores de leishmaniasis cutánea en los municipios de Otanche y Pauna, \\ por su asociación con el domicilio y por su infección natural con la misma especie de Leishmania \\ aislada de pacientes. \\ Materiales y métodos. Se recolectaron ejemplares de Lutzomyia con trampas CDC en el intra \\ y peridomicilio. La identificación del parásito se hizo, mediante PCR, a partir de muestras de \\ pacientes y en grupos de hembras de las especies de Lutzomyia más abundantes. Además se \\ confirmó la especie de parásito en muestras de pacientes por anticuerpos monoclonales. \\ Resultados. En los dos municipios, L. trapidoi fue la especie antropofílica mas abundante en \\ y alrededor de las viviendas. L. hartmanni y L. yuilli fueron también abundantes en Otanche; y, \\ L. gomezi y L. panamensis en Pauna. Leishmania (V.) panamensis se identificó tanto en \\ pacientes como en los flebótomos: L. yuilli, L. gomezi y L. panamensis. \\ Conclusión. Nuestros resultados confirman la presencia de vectores de Leishmania panamensis \\ infectados naturalmente, en las viviendas de los municipios de Otanche y Pauna del Occidente \\ de Boyacá. L. trapidoi por ser la especie más abundante puede ser considerada como el \\ vector principal. La evidencia de transmisión doméstica permite planear la aplicación de \\ medidas de control vectorial a este nivel.
}

Palabras clave: Vectores de enfermedades, Psychodidae, Leishmania, leishmaniasis, PCR, Colombia.

Presence of infected vectors of Leishmania (V.) panamensis within dwellings in two endemic foci in the foothill of the middle Magdalena valley, western Boyacá, Colombia

Introduction. Case records of leishmaniasis of the years 1997 to 2003 of the department of Boyaca showed that since the year 2000 the department experienced an unusual rise in the incidence of cutaneous leishmaniasis that might correspond to an epidemic outbreak in the western region of the department. Age and gender distribution of cases supported a domestic transmission.

Objective. This research was designed to identify the vectors of cutaneous leishmaniasis in the municipalities of Otanche and Pauna through their presence in dwellings and their natural infection with the same species of Leishmania isolated from patients.

Material and methods. Sampling of sand flies was done with CDC traps in and around dwellings. Samples from patients and pooled females of the most abundant species of Lutzomyia were used to identify the parasite by PCR. Monoclonal antibody typing was also used to confirm the identification of the parasite in samples from patients.

Results. In both municipalities $L$. trapidoi was the most abundant anthropophilic species of Lutzomyia indoors and around dwellings. L. hartmanni and L. yuilli were also abundant in 
Otanche, and L. gomezi and L. panamensis in Pauna. Leishmania (V) panamensis was identified both in patients and in the sand flies: L.yuilli, L. gomezi and L. panamensis..

Conclusion. Our findings prove the presence of infected vectors of Leishmania panamensis within dwellings in the towns of Otanche and Pauna in Western Boyacá. Since L. trapidoi was the most abundant species, it may be considered as the principal vector of Leishmania $(V$.) panamensis. The evidence of transmission within human dwellings warrants vector control at least in this environment.

Key words: disease vectors, Psychodidae, Leishmania, leishmaniasis, PCR, Colombia

Generalmente, los ciclos de transmisión de los parásitos en las leishmaniasis están definidos por la distribución geográfica de los insectos del género Lutzomyia, considerados vectores y por las preferencias de estas especies por un tipo específico de hábitat. Esta distribución y estas preferencias han cambiado en el tiempo por la influencia de factores climáticos, demográficos y procesos de deforestación que han llevado a la destrucción de los hábitat naturales de los vectores y de los animales de los cuales se alimentan (1, Vélez ID. La leishmaniosis en Colombia: de la selva a la ciudad. Memorias, XXVIII Congreso Sociedad Colombiana de Entomología, Pereira, 2001).

Esto ha ocasionado que la leishmaniasis en Colombia y en otras latitudes, haya pasado de ser una enfermedad exclusivamente selvática que afecta hombres adultos que trabajan en el bosque, para sufrir un proceso gradual de domiciliación al acentuarse las preferencias de los flebótomos por el domicilio humano, modificando el lugar y la población de mayor riesgo de infección, sin discriminación de sexo y con mayor tasa de incidencia en niños $(2,3)$.

A partir de la década de los 80 se registró en nuestro país la presencia de vectores en áreas asociadas con las viviendas (4). La misma situación se ha documentado desde entonces en estudios de foco realizados en regiones andinas (5-7), valles interandinos $(8,9)$ y en las costas Caribe (10) y Pacífica (11).

En el occidente del departamento de Boyacá la leishmaniasis cutánea tiene un carácter epidémico

Correspondencia:

Cristina Ferro, Laboratorio de Entomología, Instituto Nacional de Salud, Bogotá. crisferro@yahoo.com

Recibido: 01/08/05; aceptado: 01/03/06 desde el 2000. Para el período de 1991 al 2003 se registraron las mayores prevalencias (entre 55,4 y 6,1 casos por 1.000 habitantes), en cuatro municipios localizados en el piedemonte del Valle del Magdalena Medio: Otanche, San Pablo de Borbur, Puerto Boyacá y Pauna (12).

La enfermedad se presenta, especialmente, en el área rural y la distribución de los casos por grupos de edad y sexo indica que la población más afectada está por debajo de los 20 años, resultando un alto registro de casos en niños de 0 a 5 años y presentándose de manera similar en hombres y mujeres (Datos sin publicarse, Laboratorio de Entomología INS, Secretaría de Salud de Boyacá). Estos datos permiten inferir que, al menos, una parte de la transmisión de la enfermedad en estos municipios puede estar asociada al domicilio.

Dada la importancia de la identificación de las especies vectores y de sus preferencias por ciertos tipos de hábitat en el diseño de estrategias de control basadas en el conocimiento de la biología de estas especies, el objetivo de este estudio fue identificar los vectores de Leishmania $\mathrm{sp}$. en el ciclo de transmisión doméstico en el occidente de Boyacá, teniendo en cuenta su abundancia en los ambientes relacionados con las viviendas y la infección natural con la misma especie de Leishmania aislada de pacientes.

\section{Materiales y métodos}

\section{Área de estudio}

Se seleccionaron las veredas con mayor registro de casos. En Otanche, se eligió la vereda $\mathrm{El}$ Carmen $\left(05.7768^{\circ} \mathrm{LN}, 74.2450^{\circ} \mathrm{LO} ; 900 \mathrm{msnm}\right)$, clasificada, según las zonas de vida de Holdridge, como bosque pluvial tropical (13). En Pauna se realizó el muestreo en las veredas Topito-Quibuco (05.6531 $\left.{ }^{\circ} \mathrm{LN}, 74.0160^{\circ} \mathrm{LO}\right)$, Topo Grande 
$\left(05.6436^{\circ} \mathrm{LN}\right.$ y $\left.74.0231^{\circ} \mathrm{LO}\right)$ con una altitud aproximada de $1.100 \mathrm{msnm}$ y clasificadas como bosque húmedo tropical (13). Según el mapa de ecosistemas generales de Colombia, las áreas rurales de estos municipios del departamento de Boyacá están altamente intervenidas y, hasta 1998 , sólo conservaban $20 \%$ de la cobertura vegetal original (14).

\section{Búsqueda activa de casos y obtención de muestras de pacientes}

Con el fin de obtener muestras de las úlceras de los pacientes para la identificación de los parásitos de Leishmania, se realizó una búsqueda activa de nuevos casos. Se tomaron aspirados de las úlceras en las que el frotis detectó las formas amastigotas y se inocularon en la nariz de hámsteres dorados (Mesocricetus auratus), los cuales se trasladaron al bioterio del Instituto Nacional de Salud en Bogotá, en donde después de realizar un seguimiento a los cambios físicos, se sacrificaron entre 28 y 74 días después de la inoculación.

Se obtuvo una biopsia de la nariz de cada animal, la cual fue dividida en dos partes; una porción se maceró y se sembró en tubos con medio NNN (7), mantenidos a $27^{\circ} \mathrm{C}$ y examinados diariamente por 5 semanas en el microscopio invertido para detectar formas flageladas (15). Los cultivos positivos se llevaron a cultivo en masa para identificar los parásitos hasta el nivel de especie por anticuerpos monoclonales (15). La otra porción de biopsia se almacenó en alcohol al 70\% para identificar la especie de parásito empleando PCR para subgénero y especie, las cuales se describen más adelante.

\section{Búsqueda de vectores en el domicilio}

Se seleccionaron viviendas que tuvieran habitantes con úlceras activas o con cicatrices compatibles con leishmaniasis que expresaran haber adquirido la enfermedad recientemente (últimos 2 años) y habitar la vivienda en la misma época de la infección. Se incluyeron 38 viviendas, 17 en la vereda EI Carmen, 12 en la vereda TopitoQuibuco y 9 en la vereda Topo Grande. Para los muestreos se emplearon trampas de luz CDC activadas entre las 18:00 y las 06:00 horas del día siguiente, por dos o tres noches consecutivas, en dos meses de la estación seca y dos meses de la estación lluviosa. Las trampas se instalaron simultáneamente en cada vivienda en dos tipos de ambientes: el intradomicilio, definido en este estudio como los dormitorios ocupados de las viviendas, y el peridomicilio, definido como el ambiente que rodea la vivienda incluyendo corrales de animales domésticos a una distancia no mayor de $10 \mathrm{~m}$.

Además, se hicieron muestreos con trampas CDC y Shannon en relictos de bosques y cultivos aledaños a las viviendas entre 10 y $100 \mathrm{~m}$ de la vivienda (extradomicilio). Los insectos del género Lutzomyia capturados se almacenaron en alcohol al $70 \%$ y se mantuvieron a $-4^{\circ} \mathrm{C}$ hasta su identificación y procesamiento por PCR.

\section{Identificación taxonómica de Lutzomyia, separación y almacenamiento en grupos para búsqueda de infección natural con Leishmania}

Las hembras y los machos recolectados en los primeros muestreos fueron tratados siguiendo las modificaciones de la técnica de Young (16) y Maroli et al. (17) e identificados hasta especie empleando las claves taxonómicas de Young y Duncan (18).

Una vez obtenida la composición de especies de Lutzomyia de las zonas muestreadas, se seleccionaron aquéllas que serían almacenadas para la búsqueda de infección natural con Leishmania por PCR, de acuerdo con tres criterios: sus antecedentes como vector, su antropofilia y su abundancia en el intra y peridomicilio. Para separar estas especies de otras presentes en la zona y entre ellas mismas sin emplear el proceso químico de aclaración, se establecieron las características morfológicas externas diagnósticas tales como la pigmentación de mesonoto, la longitud de las venas en las alas y del quinto palpómero, entre otras.

La confirmación de la identificación se realizó en el $5 \%$ de los ejemplares o, por lo menos, en un ejemplar de cada especie en cada muestreo, con la observación de las espermatecas, para lo cual se disecaron los últimos segmentos del abdomen, 
se aclararon en fenol y se montaron en bálsamo de Canadá.

En un estudio previo de estandarización (19), se confirmó que para la detección de infección con Leishmania en flebotominos por PCR, con iniciadores para subgénero Leishmania (Viannia), la sensibilidad de la prueba era óptima cuando se procesaban hasta tres hembras, por lo cual en el presente estudio las hembras separadas por especie, estado trófico y presencia o ausencia de huevos maduros se almacenaron en grupos de una a tres en microtubos con alcohol al $70 \%$ y se mantuvieron a $4^{\circ} \mathrm{C}$ hasta su procesamiento por PCR.

\section{PCR para detección e identificación de Leishmania en pacientes y vectores}

La extracción del ADN de las biopsias de hámsteres inoculados y de los grupos de insectos se hizo con Chelex $100^{\circledR}$, según el protocolo presentado por Cabrera et al. (20). Se constituyó un banco de muestras con el ADN extraído de cada grupo y se almacenaron a $-20^{\circ} \mathrm{C}$ hasta ser usados como plantilla para la PCR. Se seleccionaron los iniciadores B1 (5'-GGG GTT GGT GTA ATA TAG TGG-3') y B2 (5'-CTA ATT GTG CAC GGG GAG G-3'), los cuales son específicos para el subgénero Leishmania (Viannia) y producen una banda de $750 \mathrm{pb}$, aproximadamente (21). Se hizo esta selección teniendo en cuenta que las especies del subgénero Leishmania (Viannia) son responsables de $90 \%$, aproximadamente, de los casos de leishmaniasis en Colombia (22) y la distribución geográfica conocida de las especies de Leishmania en el país indica que en la región noroccidental del departamento de Boyacá circulan especies de este subgénero (23).

Con base en estos iniciadores se realizó la PCR en el ADN extraído de las muestras de pacientes y de cada uno de los grupos de insectos. La sensibilidad y la especificidad de esta pareja de iniciadores para detectar infección por Leishmania (Viannia), así como las condiciones de amplificación ya han sido valoradas en pacientes y en flebótomos (19).

Los grupos de insectos o muestras de biopsias con amplificación positiva con los iniciadores B1 y B2, fueron sometidos a una nueva PCR con el fin de clasificar hasta especie el parásito detectado, para lo cual se emplearon los iniciadores $\mathrm{p} 1$ y $\mathrm{p} 2$, específicos para Leishmania (V.) panamensis (5'-GGT CGG ATC TGC ATG CAT CAC -3')(5'-CAA AAA GCG AGG GAC TGC GGG -3') y los iniciadores b1 y b2, específicos para Leishmania (V.) braziliensis (5'-GTG GGC GTA TCT GCT GAT GAC -3')(5'-CAA AAA GCG AGG GAC TGC GGA -3'). Estos iniciadores dirigidos a una secuencia genómica fueron reportados por Matsumoto et al. (23) y Mimori et al. (24) y sus productos de amplificación son de 79 pb para $L$. (V.) panamensis y $110 \mathrm{pb}$ para $L$. (V.) braziliensis.

En las PCR para subgénero y especie, se emplearon como controles positivos de la reacción ADN de las cepas de referencia de $L$. (V.) panamensis (MHOM/CO/87/CL-412), L. (L.) chagasi (MHOM/CO/84CL-044B) y L. (V.) braziliensis (MHOM/CO/86/CL-250) del Instituto Nacional de Salud. Como control negativo de la reacción se utilizó solución salina para las muestras de pacientes y para los grupos de insectos, ADN de una hembra de L. ovallesi proveniente de una colonia de laboratorio.

Los productos de amplificación se analizaron mediante electroforesis horizontal en geles de agarosa (NuSieve: SeaKem, 3:1) al $2 \%$, utilizando TBE 1X (89 mM Tris $\mathrm{HCl}, 90 \mathrm{mM}$ de ácido bórico y $20 \mathrm{mM}$ de EDTA, pH 8,3) como tampón de corrido. Los geles se tiñeron con $0,1 \mu \mathrm{g} / \mathrm{ml}$ de bromuro de etidio (Sigma) y los productos se visualizaron en un transiluminador de luz ultravioleta.

\section{Vectores y otras especies de Lutzomyia en las viviendas}

Teniendo en cuenta los insectos de Lutzomyia recolectados, incluyendo las hembras procesadas para la búsqueda de infección natural, se comparó la abundancia relativa de cada especie, la riqueza y la diversidad de especies en el intra y peridomicilio en cada municipio.

La abundancia relativa se calculó como el total de individuos de una especie dada sobre el número total de ejemplares recolectados; la riqueza fue 
el número de especies identificadas en cada sitio, y como índice de diversidad se calculó el de Fisher $\alpha$, de acuerdo con la ecuación $S=\alpha \ln (1+N / \alpha)$, donde $S$ es el número de especies, $\mathrm{N}$ es el número de individuos y a es una constante que representa diversidad (25). Como medida de endofagia para las especies con antecedentes de antropofilia, se hizo una relación de los ejemplares capturados en el intra y peridomicilio, la cual indica la proporción de ejemplares del peridomicilio que potencialmente entrarán a la vivienda. Además, para sustentar la endofagia se determinó el porcentaje de hembras con sangre por especie en las capturas del intradomicilio.

\section{Aspectos éticos}

Los pacientes con úlceras firmaron un consentimiento antes de que se les tomara el frotis directo y el aspirado de la lesión. Los casos positivos se remitieron al hospital del municipio, en donde recibieron tratamiento. Los habitantes de las viviendas donde se instalaron las trampas CDC fueron informados del objeto del estudio y dieron su consentimiento. Todos los procedimientos para pacientes y para animales de laboratorio fueron aprobados por el Comité de Ética del Instituto Nacional de Salud.

\section{Resultados}

\section{Especies de Lutzomyia encontradas y su relación con el domicilio}

En el cuadro 1 se presentan las especies de Lutzomyia encontradas en Otanche y Pauna, con su respectiva abundancia relativa en cada sitio de muestreo, así como los índices de endofagia $y$ el porcentaje de hembras con sangre en el intradomicilio para aquéllas antropofílicas.

Cuadro 1. Número de ejemplares recolectados, abundancia relativa e índice de endofagia de las especies de Lutzomyia en los municipios de Otanche y Pauna.

\begin{tabular}{|c|c|c|c|c|c|c|c|c|}
\hline \multirow[t]{2}{*}{$\begin{array}{l}\text { Especie de } \\
\text { Lutzomyia }\end{array}$} & \multicolumn{2}{|c|}{$\begin{array}{c}\text { Intradomicilio } \\
\left(n^{1}=47\right) \\
\%\end{array}$} & \multicolumn{2}{|c|}{$\begin{array}{c}\text { Peridomicilio } \\
\left(n^{1}=44\right) \\
\%\end{array}$} & \multicolumn{2}{|c|}{$\begin{array}{c}\text { Hembras con sangre } \\
\text { en el intradomicilio }{ }^{2} \\
\%\end{array}$} & \multicolumn{2}{|c|}{ Endofagia $^{3}$} \\
\hline & $\begin{array}{l}\text { Otanche } \\
\text { Total (185) }\end{array}$ & $\begin{array}{c}\text { Pauna } \\
\text { Total (497) }\end{array}$ & $\begin{array}{l}\text { Otanche } \\
\text { Total (664) }\end{array}$ & $\begin{array}{c}\text { Pauna } \\
\text { Total }(1.926)\end{array}$ & Otanche & Pauna & Otanche & Pauna \\
\hline L. trapidoi & 43,2 & 30,4 & 53,6 & 18,2 & 27,5 & 35,1 & 0,22 & 0,42 \\
\hline L. hartmanni & 26,5 & 2,4 & 11,3 & 0,7 & 2,1 & 0 & 0,65 & \\
\hline L. yuilli yuilli & 10,3 & 4,4 & 14,0 & 11,3 & 10,5 & 40,9 & 0,20 & 0,10 \\
\hline L. gomezi & 0 & 24,3 & 0 & 26,1 & & 30,6 & & 0,24 \\
\hline L. panamensis & 0 & 20,7 & 0 & 34,4 & & 13,6 & & 0,15 \\
\hline L. triramula & 11,3 & 0 & 13,5 & 0,1 & & & & \\
\hline L. ovallesi & 1,1 & 3,6 & 0,1 & 1,6 & & & & \\
\hline L. barretoi majuscula & 0,5 & 0 & 2,7 & 0 & & & & \\
\hline L. dubitans & 1,1 & 0 & 1,2 & 0 & & & & \\
\hline L. walkeri & 2,1 & 2,8 & 1,5 & 1,2 & & & & \\
\hline L. trinidadensis & 1,1 & 0 & 0,1 & 0 & & & & \\
\hline L. camposi & 0 & 4,8 & 0,3 & 3,9 & & & & \\
\hline L. shannoni & 0,5 & 0,2 & 0,1 & 0,1 & & & & \\
\hline L. saulensis & 1,6 & 2,2 & 0,9 & 0,7 & & & & \\
\hline L. sordelli & 0 & 0 & 0,4 & 0,4 & & & & \\
\hline L. serrana & 0,5 & 2,0 & 0 & 0,2 & & & & \\
\hline L. ayrozai & 0 & 0,2 & 0 & 0,2 & & & & \\
\hline L. lichyi & 0 & 1,4 & 0 & 0,6 & & & & \\
\hline L. dysponeta & 0 & 0,4 & 0 & 0,2 & & & & \\
\hline$\alpha$ de Fisher & 2,86 & 2,67 & 2,29 & 2,39 & & & & \\
\hline
\end{tabular}

\footnotetext{
$1 \mathrm{n}$ : número total de muestreos

2 Porcentaje de hembras con sangre en el intradomicilio para especies antropofílicas

${ }^{3}$ Endofagia para las especies antropofílicas = número de ejemplares capturados en el intradomicilio/número de ejemplares capturados en el peridomicilio
} 
En el municipio de Otanche, en la vereda El Carmen, se recolectaron 849 individuos del género Lutzomyia, 185 en el intradomicilio y 664 en el peridomicilio. La riqueza de especies fue similar y se encontraron 12 especies en las capturas del intradomicilio y 13 en el peridomicilio. En ambos sitios, L. trapidoi fue predominante, 43,2 y $53,6 \%$ en intra y peridomicilio, respectivamente. En el intradomicilio le siguieron en abundancia $L$. hartmanni (26,5\%), L. triramula (11,3\%) y L. yuilli (10,3\%) y en el peridomicilio, L. yuilli $(14,0 \%), L$. triramula $(13,5 \%)$ y L. hartmanni $(11,3 \%)$. En cuanto al índice de endofagia, $L$. hartmanni y $L$. trapidoipresentaron los mayores valores, mientras que las especies con mayor porcentaje de hembras con sangre en el intradomicilio fueron $L$. trapidoi y L. yuilli.

L. triramula se encontró con frecuencia en el intra y en el peridomicilio en Otanche. Esta especie no es antropofílica; sin embargo, es atraída por la luz $(26,27)$, lo que explica su abundancia en las capturas realizadas con trampas que utilizan la luz como estímulo de atracción.

En Pauna, en las veredas Topito-Quibuco y Topo Grande, se recolectaron 2.423 individuos, 497 (14 especies) y 1.926 (16 especies) en el intra y peridomicilio, respectivamente. En el intradomicilio predominaron L. trapidoi $(30,4 \%)$, L. gomezi $(24,3 \%)$ y $L$. panamensis $(20,7 \%)$ y en el peridomicilio, las mismas especies con diferentes abundancias, L. panamensis (34,4\%), L. gomezi $(26,1 \%)$ y $L$. trapidoi $(18,2 \%)$. Los mayores índices de endofagia fueron para $L$. trapidoi y $L$. gomezi y los porcentajes de hembras con sangre en el intradomicilio fueron altos en $L$. yuilli y $L$. trapidoi.

Las demás especies se presentaron con abundancias bajas, inferiores al $5 \%$, en los ambientes muestreados. La diversidad de especies fue ligeramente mayor en el intradomicilio en ambos municipios, debido a que en un número reducido de ejemplares se identificó un número considerable de especies. De las demás especies encontradas se resaltan algunas antropofílicas y con antecedentes vectoriales como $L$. ovallesi y L. shannoni; sin embargo, por su baja abundancia (menor al $1 \%$ ) se descarta que puedan estar involucradas en la transmisión de la enfermedad en ambientes asociados al domicilio.

\section{Detección e identificación de Leishmania en pacientes y en grupos de Lutzomyia spp.}

De las úlceras cutáneas de siete pacientes positivos en Otanche y seis en Pauna, se tomaron aspirados y se inocularon en hámsteres, de los cuales, permitieron el desarrollo del parásito 3 y 2 hámsteres, respectivamente.

Se obtuvieron cultivos viables del parásito a partir de biopsias de dos hámsteres procedentes de cada uno de los dos municipios, los cuales fueron identificados por anticuerpos monoclonales como de la especie $L$. (V.) panamensis.

Todas las biopsias procesadas por PCR, produjeron la banda diagnóstica de 750 pb con los iniciadores para el subgénero Leishmania (Viannia). Al realizar la PCR especie-específica, se obtuvo amplificación positiva con los iniciadores para la especie $L$. (V.) panamensis en cinco de las biopsias y con los iniciadores para L. (V.) braziliensis en una biopsia correspondiente a un paciente de Pauna.

En cuanto a la infección natural con Leishmania en hembras de Lutzomyia, el cuadro 2 presenta el número de hembras procesadas por PCR para cada especie y el número de grupos con amplificación positiva para Leishmania (Viannia), empleando los iniciadores B1 y B2. Aparecen, además, los porcentajes de infección para cada especie y el sitio de recolección de las hembras con respecto a las viviendas. En la figura 1 se aprecia la visualización del producto de amplificación con los iniciadores B1 y B2 para uno de los grupos.

En el municipio de Otanche se obtuvieron 2 grupos positivos, ambos de L. yuilli, sin ingestión de sangre, ni huevos maduros, procedentes del peridomicilio de una vivienda.

En el municipio de Pauna se detectó el parásito en cuatro grupos, tres de la especie $L$. panamensis y uno de L. gomezi.

Dos de los grupos positivos de L. panamensis correspondían a hembras sin sangre ni huevos maduros, capturadas en el peridomicilio de una 
Cuadro 2. Infección natural por Leishmania panamensis detectada por PCR en grupos de Lutzomyia spp. en los municipios de Otanche y Pauna.

\begin{tabular}{|c|c|c|c|c|c|c|c|c|c|c|}
\hline \multirow{3}{*}{ Especie } & \multicolumn{10}{|c|}{ N. total de hembras procesadas por PCR (No. positivas para Leishmania*) en cada municipio } \\
\hline & \multicolumn{5}{|c|}{ Otanche } & \multicolumn{5}{|c|}{ Pauna } \\
\hline & $\begin{array}{c}\text { Intra- } \\
\text { domicilio }\end{array}$ & $\begin{array}{c}\text { Peri- } \\
\text { domicilio }\end{array}$ & $\begin{array}{c}\text { Extra- } \\
\text { domicilio }\end{array}$ & $\begin{array}{l}\text { Total por } \\
\text { especie }\end{array}$ & $\begin{array}{c}\% \text { de } \\
\text { infección }^{\star \star}\end{array}$ & $\begin{array}{c}\text { Intra- } \\
\text { domicilio }\end{array}$ & $\begin{array}{c}\text { Peri- } \\
\text { domicilio }\end{array}$ & $\begin{array}{c}\text { Extra- } \\
\text { domicilio }\end{array}$ & $\begin{array}{l}\text { Total por } \\
\text { especie }\end{array}$ & $\begin{array}{c}\% \text { de } \\
\text { infección }^{\star \star}\end{array}$ \\
\hline L. hartmanni & $5(0)$ & $47(0)$ & $20(0)$ & $72(0)$ & 0 & $7(0)$ & $6(0)$ & - & $13(0)$ & 0 \\
\hline L. gomezi & - & - & - & - & - & $45(0)$ & $111(1)$ & $54(0)$ & $210(1)$ & 0,5 \\
\hline L. panamensis & - & - & - & - & - & $64(0)$ & $334(3)$ & $98(0)$ & $496(3)$ & 0,6 \\
\hline L. trapidoi & $15(0)$ & $302(0)$ & $91(0)$ & $408(0)$ & 0 & $74(0)$ & $75(0)$ & $28(0)$ & $177(0)$ & 0 \\
\hline L. yuilli & $6(0)$ & $71(2)$ & $44(0)$ & $121(2)$ & 1,6 & $13(0)$ & $61(0)$ & $6(0)$ & $80(0)$ & 0 \\
\hline $\begin{array}{l}\text { Total por sitio } \\
\text { de muestreo }\end{array}$ & $26(0)$ & $420(2)$ & $155(0)$ & $601(2)$ & & $203(0)$ & $587(4)$ & $186(0)$ & $976(4)$ & \\
\hline
\end{tabular}

* Los números entre paréntesis indican el número de grupos positivos para Leishmania.

** Porcentaje de hembras infectadas, asumiendo una hembra infectada por grupo positivo

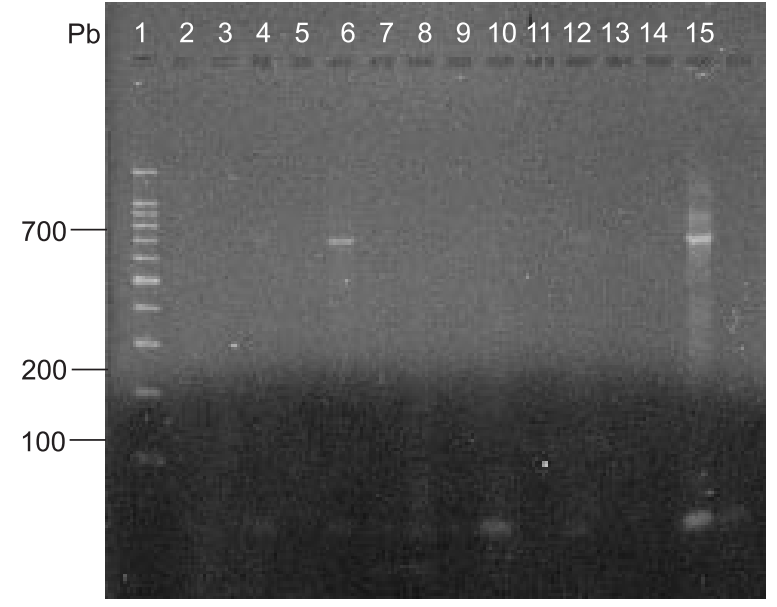

vivienda, en la que en la misma época de la captura (noviembre de 2002) se encontraron dos habitantes con úlceras activas y examen directo positivo.

El otro grupo positivo de L. panamensis, correspondió a hembras con huevos maduros, capturadas en un peridomicilio de la vereda Topo Grande.

El grupo positivo de L. gomezi correspondía a hembras con sangre, capturadas en el peridomicilio de una vivienda de la vereda Topito y Quibuco.

Los seis grupos positivos para Leishmania (Viannia) con los iniciadores B1 y B2, fueron procesados nuevamente con los iniciadores especie-específicos, y se obtuvo amplificación para $L$. (V.) panamensis (figura 2) en todos los
Carril 1: marcador de peso molecular

Carril 2-5 y 7-13: grupos de L. panamensis negativos para Leishmania (Viannia)

Carril 6: grupo de Lutzomyia yuilli positivo para Leishmania (Viannia)

Carril 14: control negativo: ADN de 1 hembra de $L$. ovallesi de la colonia de laboratorio (INS)

Carril 15: control positivo: cultivo de L.(V.) panamensis, cepa de referencia (INS)

Figura 1. Detección de ADN de Leishmania (Viannia) con los iniciadores B1 y B2 en un grupo de hembras de Lutzomyia yuilliprocedentes del peridomicilio de una vivienda de Otanche.

grupos. No se observaron productos de amplificación al procesar los insectos con los iniciadores b1 y b2, específicos para $L$. (V.) braziliensis (no se muestra el gel).

\section{Discusión}

La infección natural es uno de los criterios más importantes en la incriminación de una especie de Lutzomyia como vector de Leishmania (28) y es el que presenta mayor dificultad en su demostración $(29,30)$. Actualmente, la PCR es una técnica de alta sensibilidad utilizada con frecuencia en los estudios epidemiológicos de leishmaniasis para la detección e identificación del parásito en pacientes, reservorios y vectores. Es así como se ha detectado infección natural por Leishmania en varias poblaciones de flebótomos en Perú, Venezuela y Bolivia (31-33). 


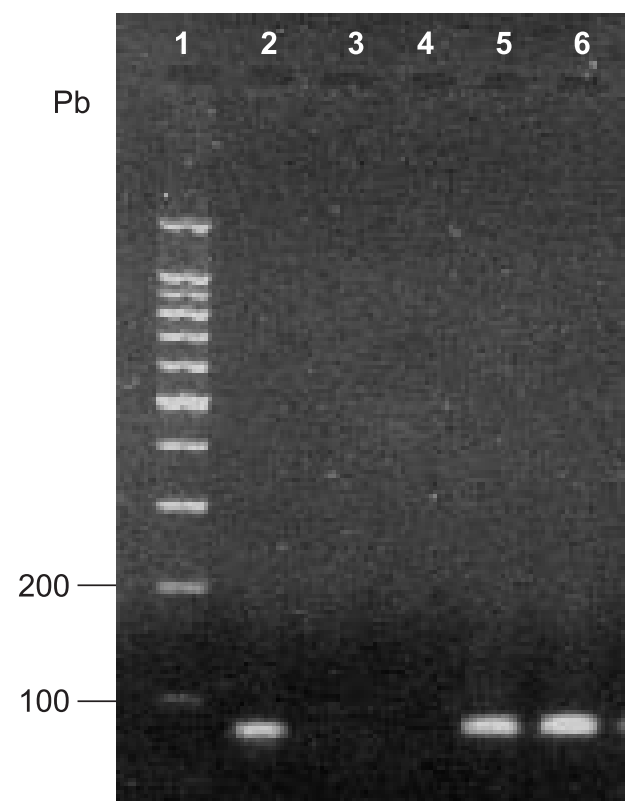

En el presente estudio, la PCR con los iniciadores B1 y B2 permitió detectar infección natural con Leishmania (Viannia) en tres de las cinco especies de Lutzomyia procesadas con esta técnica. Posteriormente, se estableció con los iniciadores especie-específicos que los grupos positivos contenían el parásito $L$. (V.) panamensis, el cual fue aislado e identificado de pacientes provenientes de las mismas veredas en las que se realizaron los muestreos de los flebotomíneos en ambos municipios.

Aunque, en este estudio $L$. trapidoino fue hallada naturalmente infectada con Leishmania, Molina (34) en el área rural del municipio de Otanche encontró formas flageladas en 64 hembras de esta especie. Sin embargo, el intento de aislamiento y cultivo de los parásitos fue infructuoso. Por otro lado, en el foco de leishmaniasis cutánea ubicado en Landázuri, Santander, Muñoz (35) disecó 558 hembras de $L$. trapidoi y observó flagelados en 11 hembras, 2 de las cuales resultaron positivas para parásitos del subgénero Leishmania (Viannia).

L. trapidoi es un vector confirmado de $L$. (V.) panamensis en otros focos de leishmaniasis cutánea en Colombia (11,29,35,36,), Panamá (37) y Ecuador (38). Es antropofílica y su capacidad
Carril 1: marcador de peso molecular

Carril 2: control positivo, cultivo de L. (V.) panamensis, cepa de referencia (INS)

Carril 3: control negativo, solución salina

Carril 4: cultivo de $L$ (V.) braziliensis, cepa de referencia (INS)

Carril 5: ADN extraído de biopsia de hámster inoculado con aspirado de una lesión activa de un paciente del municipio de Pauna

Carril 6: grupo de hembras de Lutzomyia gomezi

Figura 2. Productos de amplificación de la PCR con iniciadores especie-específicos para Leishmania (Viannia) panamensis en una muestra de un paciente de Pauna y en un grupo de Lutzomyia gomezi de la misma localidad.

para soportar el desarrollo de $L$. (V.) panamensis se ha confirmado en el laboratorio (39). En el presente estudio, $L$. trapidoi fue la especie más abundante en el intradomicilio en ambos municipios y en el peridomicilio, también, presentó una abundancia importante. Además, fue en la que más se registró presencia de sangre en las capturas del intradomicilio lo que indica indirectamente su habilidad para alimentarse en el interior de las viviendas. Estas características indican que $L$. trapidoi puede ser el vector primario de la enfermedad en estos municipios y participar en la transmisión de la enfermedad a nivel domiciliario.

En el municipio de Otanche se detectó infección por L. (V) panamenisis en dos grupos de L. yuilli. En hembras disecadas de esta especie ya se habían encontrado flagelados en Colombia (4) y Brasil $(40,41)$ pero no se habían logrado identificar. Éste se constituye en el primer reporte de infección con parásitos identificados de Leishmania en L. yuilli. En cuanto a su asociación con el domicilio humano, en el área de estudio, $L$. yuilli se encontró en el intra y peridomicilio en ambos municipios, lo que sugiere que podría estar participando en el ciclo de transmisión doméstico 
de la enfermedad, especialmente, en Otanche donde este vector es más frecuente. Esta especie había sido considerada como exclusiva de áreas boscosas en diferentes países de Suramérica (16) pero en los últimos años se ha demostrado su adaptación a ambientes modificados por el hombre encontrándose en cultivos, en el peri e intradomicilio $(42,43)$ y se ha demostrado su carácter antropofílico $(44,45)$.

En el municipio de Pauna, L. panamensis y $L$. gomezi presentaron infección natural con $L$. (V.) panamensis; la primera presenta una amplia distribución en Colombia, es antropofílica y vector comprobado de $L$. (V.) panamensis en Panamá (37); también, ha sido incriminada en la transmisión de $L$. (V.) braziliensis en Venezuela (46) y encontrada con flagelados no identificados en Ecuador (47). En Colombia es la primera vez que se reporta infección natural por L.(V.) panamensis en 3 hembras de esta especie. Uno de los grupos en los que se diagnosticó la presencia del parásito $L$. (V.) panamensis correspondía a una hembra que presentaba huevos maduros, lo que indica indirectamente que la especie puede soportar el desarrollo del parásito, permitiendo su multiplicación, aún después de la digestión de la sangre, por lo que se considera un vector potencial en el domicilio (48).

Por su parte, L. gomezi, es una especie reconocida por su comportamiento antropofílico y endofílico, es considerada como probable vector en varias regiones endémicas de leishmaniasis cutánea en Colombia $(2,11,35)$; además, ha sido encontrada naturalmente infectada con promastigotes no identificados en Panamá (49), Ecuador (50) y Colombia $(29,36)$. Recientemente, en Venezuela fue encontrada naturalmente infectada con parásitos identificados como $L$. braziliensis $(46,51)$. La presencia de alimento sanguíneo en la hembra de $L$. gomezi encontrada infectada en este estudio llevaría a discutir dos posibilidades: la primera es que la hembra se haya alimentado horas antes de la captura de un reservorio infectado o que se haya infectado con Leishmania en una primera alimentación y que acabara de tomar su segunda o tercera alimentación de sangre, lo cual colocaría a esta especie como un vector eficiente de Leishmania (48). Se ha demostrado en infecciones experimentales que $L$. gomezi permite el completo desarrollo de $L$. (V.) panamensis en su tracto digestivo $(39,52)$.

Tanto L. panamensis como L. gomezi, en el municipio de Pauna, fueron abundantes en el intra y peridomicilio, lo cual está acorde con otros reportes en los que se demuestra su habilidad para adaptarse a ambientes modificados (53). Además, se ha verificado su ingreso al intradomicilio en diferentes focos de la enfermedad tanto en áreas rurales como periurbanas y urbanas $(54,55)$.

En el presente estudio, los porcentajes de infección natural en las especies procesadas oscilaron entre 0,5 (para L. gomezi) y $1,6 \%$ (para L. yuilli), lo cual está acorde con los porcentajes encontrados en otras especies de Lutzomyia en Suramérica empleando la PCR $(23,25)$ y el método convencional $(29,56,57)$. L. yuilli presentó el mayor porcentaje de infección natural, el cual posiblemente está asociado con una alta abundancia estacional de esta especie en la época en que se realizó el muestreo. Por otro lado, el sitio en el que fueron recolectados los ejemplares encontrados naturalmente infectados con Leishmania en este estudio fue el peridomicilio, lo cual sugiere el lugar donde estas especies actúan como vectores.

L. yuilli, L. gomezi y L. panamensis cumplen con varios de los criterios propuestos por KillickKendrick (28) para ser incriminadas como vectores de $L$. (V.) panamensis en la zona de estudio. Son especies antropofílicas, tienen antecedentes vectoriales reportados, se presentan con abundancia en el peridomicilio en donde se cree que ocurre la transmisión y fueron encontradas infectadas con la misma especie de Leishmania aislada de pacientes. Se sugiere, entonces, que estas especies toman parte en el ciclo doméstico de transmisión del parásito en la región.

Por su parte, L. hartmannies el vector comprobado de Leishmania colombiensis en Colombia; es una especie antropofílica y se encontró con frecuencia en el intradomicilio en el municipio de Otanche; sin embargo, su papel como vector de $L$. (V.) panamensis en la zona de estudio está por determinarse. 
La colonización humana en las áreas rurales de los municipios estudiados es relativamente reciente y se ha acompañado de una progresiva devastación de los bosques ya sea para la explotación de la madera, implementar cultivos o la construcción de viviendas. Esto ha ocasionado una disminución en la diversidad de las especies de flebótomos y de los animales silvestres de los cuales se alimentan, por lo cual prevalecen aquellas especies de Lutzomyia que se adaptan mejor a los ambientes modificados y ocupados por el hombre. En estos ambientes las especies de flebótomos llegan a presentarse en altas densidades ya que encuentran su supervivencia garantizada gracias a la estrecha relación con el hombre y sus animales domésticos y esta circunstancia incrementa el riesgo para los habitantes de las zonas rurales de adquirir la enfermedad en el interior de su domicilio o en el ambiente circundante al mismo (58).

Las especies más abundantes en el intra y peridomicilio en ambos municipios, $L$. trapidoi, $L$. hartmanni y $L$. yuilli en Otanche y $L$. trapidoi, $L$. gomezi y L. panamensis en Pauna, demostraron adaptarse exitosamente a hábitats degradados, son antropofílicas y se confirmó la presencia del parásito en tres de ellas por lo que se concluye que están involucradas en el ciclo doméstico de transmisión del parásito en la región.

En los últimos años la domiciliación de la transmisión de la leishmaniasis se ha reportado de manera frecuente en Latinoamérica (59), lo cual como es discutido por Campbell et al. (59), presenta posibilidades de control a nivel doméstico. Sin embargo, para que las medidas de control sean exitosas se recomienda que, además de la definición de los vectores, se estudien parámetros de comportamiento como la actividad horaria de picadura y la endofilia de cada vector.

\section{Agradecimientos}

A Ángela Sandoval de la Secretaría de Salud de Boyacá por su colaboración en la toma y diagnóstico de los frotis directos; a las autoridades de salud de los municipios de Otanche y Pauna por su colaboración en la organización de las salidas de campo; a Tania Tibaduiza y Marco Fidel
Suárez por su ayuda en la recolección del material entomológico; a la comunidad de las veredas en donde se realizaron los muestreos por su colaboración.

\section{Conflicto de interés}

No hay conflicto de interés.

\section{Financiación}

Instituto Nacional de Salud, Colciencias (proyecto código 2104-04-12677) y Secretaría de Salud de Boyacá.

\section{Referencias}

1. World Health Organization. Leishmaniasis. (Consultado el 15 de mayo de 2004). Disponible en: http://www.who.int/inf-fs/en/fact116.html, 2000.

2. Vélez ID, Wolff M, Valderrama R, Escobar JP, Osorio L. Community and environmental risk factors associated with cutaneous leishmaniasis in Montebello, Antioquia, Colombia. En: IDRC, editors. Leishmaniasis control strategies: a critical evaluation of IDRCsupported research. London: IDRC Publications; 1991. p.261-74.

3. Davies CR, Reithinger R, Campbell-Lendrum D, Feliciangeli $\mathbf{D}$, Borges $\mathbf{R}$, Rodriguez $\mathbf{N}$. The epidemiology of leishmaniasis in Andean countries. Cad Saúde Pública 2000;16:925-50.

4. Ferro C, Morales A. Flebótomos de Colombia: Estudios realizados por el laboratorio de entomología 1966-1997. En: Toro G, Hernández CA, Raad J, editores. Instituto Nacional de Salud 1917-1997: una historia, un compromiso. Bogotá: Instituto Nacional de Salud; 1998. p.219-33.

5. Martinez G, Uribe S, Velez ID. Behavior and intradwelling-vertical-distribution of Lutzomyia (L.) gomezi, Nitzulescu 1931 in Montebello, Antioquia, Colombia. Bol Dir Malariol San Amb 1995;35:197-204.

6. Cárdenas R, Romo GM, Santamaría E, Bello F, Ferro C. Lutzomyia longiflocosa (Diptera: Psychodidae) posible vector en el foco de leishmaniasis cutánea del municipio de Planadas, zona cafetera del Tolima. Biomédica 1999;19:239-44.

7. Alexander B, Agudelo A, Navarro F, Ruiz F, Molina J, Aguilera G et al. Phlebotomine sandflies and leishmaniasis risks in Colombian coffee plantations under two systems of cultivation. Med Vet Entomol 2001;15:364-73.

8. Montoya-Lerma J, Cadena H, Segura I, Travi BL. Association of Lutzomyia columbiana (Diptera: Psychodidae) with a leishmaniasis focus in Colombia due to species of the Leishmania mexicana complex. Mem Inst Oswaldo Cruz 1999;94:277-83. 
9. Ferro C, Morrison AC, Torres M, Pardo R, Wilson ML, Tesh RB. Age structure, blood-feeding behavior, and Leishmania chagasi infection in Lutzomyia longipalpis (Diptera: Psychodidae) at an endemic focus of visceral leishmaniasis in Colombia. J Med Entomol 1995;32:618-29.

10. Travi BL, Montoya J, Gallego J, Jaramillo C, Llano R, Vélez ID. Bionomics of Lutzomyia evansi (Diptera: Psychodidae) vector of visceral leishmaniasis in northern Colombia. J Med Entomol 1996;33:278-85.

11. Travi BL, Montoya J, Solarte Y, Lozano L, Jaramillo C. Leishmaniasis in Colombia. I. Studies on the phlebotomine fauna associated with endemic foci in the Pacific coast region. Am J Trop Med Hyg 1988;39:261-6.

12. Tibaduiza T. Evaluación del uso de toldillos impregnados con piretroide como medida para reducir la abundancia intradomiciliar de especies del género Lutzomyia, implicadas en la transmisión de leishmaniasis cutánea, en el municipio de Pauna, Boyacá (tesis). Bogotá: Universidad Nacional; 2006.

13. Espinal S. Zonas de vida o formaciones vegetales de Colombia. Memoria explicativa sobre el mapa ecológico. Bogotá: Instituto Geográfico "Agustín Codazzi" (IGAC); 1978. p.1-238.

14. Etter E. Mapa general de ecosistemas de Colombia. En: Chaves ME, Arango M, editores. Informe nacional sobre el estado de la biodiversidad en Colombia. Tomo I. Diversidad biológica. Instituto de Investigación de Recursos Biológicos Alexander Von Humboldt, PNUMA, Bogotá: Ministerio del Medio Ambiente; 1997. p.1-150.

15. Duque S, Peláez D, Corredor A. Normas para cultivo in vitro de parásitos de la familia Trypanosomatidae. Manual de procedimientos. Bogotá: Instituto Nacional de Salud; 1993.

16. Young DG. A review of the bloodsucking psychodid flies of Colombia (Diptera: Phlebotominae and Sycoracinae). Tech Bull 806. Gainesville: Universidad de la Florida; 1979. p.226.

17. Maroli M, Feliciangeli MD, Arias J. Métodos de captura, conservación y montaje de los flebótomos (Diptera: Psychodidae). Washington: Organización Panamericana de la Salud; 1997. p.1-72.

18. Young DG, Duncan MA. Guide to the identification and geographic distribution of Lutzomyia sand flies in México, West Indies, Central and South America (Diptera: Psychodidae). Mem Am Entomol Inst 1994;54:1-881.

19. Santamaría E, Ponce NB, Puerta C, Ferro C. Validación de la PCR en la detección de parásitos de Leishmania (Viannia) spp. en Lutzomyia (Diptera: Psychodidae), como herramienta en la definición de especies vectores. Biomédica 2005;25:271-9.

20. Cabrera OL, Munstermann LE, Cárdenas R, Gutiérrez R, Ferro C. Definición de las condiciones de temperatura y almacenamiento adecuadas en la detección de ADN de Leishmania por PCR en flebotominos. Biomédica 2002;22:296-302.

21. de Bruijn MH, Barker DC. Diagnosis of New World leishmaniasis: specific detection of species of the Leishmaniasis braziliensis complex by amplification of kinetoplast DNA. Acta Trop 1992;52:45-58.

22. Corredor A, Kreutzer RD, Tesh RB, Boshell J, Palau MT, Cáceres E et al. Distribution and etiology of leishmaniasis in Colombia. Am J Trop Med Hyg 1990;42:206-14.

23. Matsumoto T, Hashiguchi Y, Gomez EA, Calvopiña MH, Nonaka S, Saya H et al. Comparison of PCR results using scrape/exudate, syringe-sucked fluid and biopsy samples for diagnosis of cutaneous leishmaniasis in Ecuador. Trans R Soc Trop Med Hyg 1999;93:606-7.

24. Mimori T, Matsumoto T, Calvopiña MH, Gomez EA, Saya $\mathrm{H}$, Katakura $\mathrm{K}$ et al. Usefulness of sampling with cotton swab for PCR-diagnosis of cutaneous leishmaniasis in the New World. Acta Trop 2002;81:197202.

25. Fisher RA, Cobert AS, Williams CB. The relation between the number of species and the number of individuals in a random sample of an animal population. J Animal Ecol 1943;12:42-57.

26. Chaniotis BN, Correa MA. Comparative flying and biting activity of Panamian phlebotomine sand flies in mature forest and adjacent open space. J Med Entomol 1974;11:115-6.

27. Rutledge LC, Ellenwood DA, Johnston L. An analysis of sandfly light trap collection in the Panama Canal Zone (Diptera: Psychodidae). J Med Entomol 1975;12:179-83.

28. Killick-Kendrick R. Phlebotomus vectors of the leishmaniasis: a review. Med Vet Entomol 1990;4:1-24.

29. Young DG, Morales A, Kreutzer RD, Alexander B, Corredor A, Tesh RB et al. Isolations of Leishmania braziliensis (Kinetoplastida: Trypanosomatidae) from cryopreseved Colombian sandflies (Diptera: Psychodidae). J Med Entomol 1987;24:587-9.

30. Kreutzer RD, Corredor A, Grimaldi JR, Grogl M, Rowton ED, Young DG et al. Characterization of Leishmania colombiensis sp.n. (Kinetoplastida: Trypanosomatidae), a new parasite infecting humans, animals, and phlebotomine sand flies in Colombia and Panama. Am J Trop Med Hyg 1991;44:662-75.

31. Pérez JE, Ogusuku E, Inga R, López M, Monje J, Paz L et al. Natural Leishmania infection of Lutzomyia spp. in Peru. Trans R Soc Trop Med Hyg 1994;88:161-4.

32. Jorquera A, Gonzalez R, Marchan-Marcano E, Oviedo M, Matos M. Multiplex PCR for detection of natural Leishmania infection in Lutzomyia spp. captured in an endemic region for cutaneous leishmaniasis in 
state of Sucre, Venezuela. Mem Inst Oswaldo Cruz 2005; $100: 45-8$

33. Torrez M, López M, Le Pont F, Martínez E, Muñoz M, Hervas D et al. Lutzomyia nuñeztovari anglesi (Diptera: Psychodidae) as a probable vector of Leishmania braziliensis in the Yungas, Bolivia. Acta Trop 1998;71:311-6.

34. Molina JA. Determinación de la fauna flebotominea en el noroccidente de Boyacá. Implicación de Lutzomyia trapidoi como especie vectora en el foco de leishmaniasis de la Zambera (trabajo de grado). Bogotá: Universidad de los Andes; 1995. p.98.

35. Muñoz G. The sandfly vectors and epidemiology of cutaneous leishmaniasis in the Landázuri focus, Colombia (tesis). Londres: University of London; 1998. p.257.

36. Morales A, Corredor A, Cáceres E, Ibagos AL, Rodríguez Cl. Aislamiento de tres cepas de Leishmania a partir de Lutzomyia trapidoi en Colombia. Biomédica 1981;4:37-41.

37. Christensen HA, Fairchild GB, Herrer A, Johnson CM, Young DG, De Vasquez AM. The ecology of cutaneous leishmaniasis in the Republic of Panama. J Med Entomol 1983;20:463-84.

38. Hashiguchi Y, Gomez EA, De Coronel VV, Mimori T, Kawabata M. Biting activity of two antropophilic species of sandflies, Lutzomyia, in an endemic area of leishmaniasis in Ecuador. Ann Trop Med Parasitol 1985;79:533-8.

39. Jaramillo C, Travi BL, Montoya J. Vector competence of some Neotropical sandflies for the Leishmania (Viannia) braziliensis complex. Med Vet Entomol 1994;8:1-7.

40. Lainson R, Ryan L, Shaw JJ. Infective stages of Leishmania in the sand fly vector and some observations on the mechanism of transmission. Mem Inst Oswaldo Cruz 1987;82:421-4.

41. Arias JR, Miles MA, Naiff RD, Povoa MM, De Freitas RA, Bianciardi CB et al. Flagellate infections of Brazilian sand flies (Diptera: Psychodidae): isolation in vitro and biochemical identification of Endotrypanum and Leishmania. Am J Trop Med Hyg 1985;34:1098-108.

42. Alexander B, Agudelo LA, Navarro F, Ruiz F, Molina J, Aguilera G et al. Phlebotomine sandflies and leishmaniasis risk in Colombian coffee plantations under two systems of cultivation. Med Vet Entomol 2001;15:364-73.

43. López Y, Osorio L, Álvarez G, Rojas J, Jiménez F, Gómez $\mathbf{C}$ et al. Sandfly Lutzomyia longipalpis in a cutaneous leishmaniasis focus in Central Colombia. Mem Inst Oswaldo Cruz 1996;91:415-9.

44. Wolff M, Sierra D, Murcia LM, Vélez ID. Phlebotomine fauna (Diptera: Psychodidae) in the department of Amazonas, Colombia. Neotrop Entom 2003;32:523-6.
45. Young DG, Porter CH. Lutzomyia yuilli a new manbiting phlebotomine sand fly from Colombia (Diptera: Psychodidae). J Med Entomol 1972;9:524-6.

46. Rodríguez N, Aguilar CM, Barrios MA, Barker DC. Detection of Leishmania braziliensis in naturally infected individual sand flies by the polymerase chain reaction. Trans R Soc Trop Med Hyg 1999;93:47-9.

47. World Health Organization. The leishmaniasis. Technical Report Series No. 793, Geneva: World Health Organization; 1984. p.120.

48. Lane RP. Sandflies (Phlebotominae). In: Lane RP, Crosskey RW, editors. Medical insects and arachnids. Cambridge: Chapman and Hall; 1993. p.78-119.

49. Johnson PT, Mcconell E, Hertig M. Natural infections of leptomonad flagellated in Panamian Phlebotomus sandflies. Exp Parasitol 1963;14:107-22.

50. Gómez EA, Hashiguchi Y. Vector entomology. 1. Natural infections of sand flies with Leishmania promastigotes. En: Hashiguchi $\mathrm{Y}$, editor. Studies on New World leishmaniasis and its transmission, with particular reference to Ecuador. Kochi: Kyowa Printing; 1987. p.70-8.

51. Feliciangeli MD, Rodriguez N, Bravo A, Arias $F$, Guzmán B. Vectors of cutaneous leishmaniasis in north-central Venezuela. Med Vet Entomol 1994;8:31724

52. Walters LL, Chaplin GL, Modi GB, Tesh RB. Ultrastructural biology of Leishmania (Viannia) panamensis (=Leishmania braziliensis panamensis) in Lutzomyia gomezi (Diptera: Psychodidae): a natural host-parasite association. Am J Trop Med Hyg 1989;40:19-39.

53. Travi BL, Adler GH, Lozano M, Cadena H, MontoyaLerma J. Impact of habitat degradation on phlebotomine (Diptera: Psychodidae) of tropical dry forest in northern Colombia. J Med Entomol 2002;39:451-6.

54. Bejarano E, Uribe S, Rojas W, Velez ID. Phlebotomine sand flies (Diptera: Psychodidae) associated with the appearance of urban leishmaniasis in the city of Sincelejo, Colombia. Mem Inst Oswaldo Cruz 2002;97:645-7.

55. Vargas GS, Álvarez G, Wolff M, López Y, Gómez ME. Estudio de un foco de leishmaniasis en dos barrios de Remedios, Antioquia. Boletín Epidemiológico de Antioquia 1990;16:48-59.

56. Ryan L, Vexenat A, Marsden PD, Lainson R, Shaw JJ. The importance of rapid diagnosis of new cases of cutaneous leishmaniasis in pin-pointing the sandfly vector. Trans R Soc Trop Med Hyg 1990;84:786-8.

57. Rangel EF, Souza NA, Wermelinger DE, Barbosa AF. Natural infection of Lutzomyia intermedia Lutz \& Neiva, 1912, in an endemic area of visceral leishmaniasis of Rio de Janeiro. Mem Inst Oswaldo Cruz 1984;79:395-6. 
58. Aguiar GM, Medeiros WM, De Marco TS, Santos SC, Gambardella S. Ecology of sandflies in Serra do Mar, Itaguai, state of Rio de Janeiro, Brazil. I - Sandfly fauna and prevalence of the species in collections sites and method of capture. Cad Saude Publica 1996;12:195-206.
59. Campbell-Lendrum D, Dujardin JP, Martinez E, Feliciangeli MD, Perez JE, Silans LN et al. Domestic and peridomestic transmission of American cutaneous leishmaniasis: changing epidemiological patterns present new control opportunities. Mem Inst Oswaldo Cruz 2001;96:159-62. 